\title{
Study on Hydrodynamic Characteristics of Wind Turbine Monopile under Nonlinear Wave
}

\author{
Zou Li ${ }^{12^{*}}$, Yang Kexin ${ }^{1}$, Sun Tiezhi ${ }^{1}$, Wang Peizheng ${ }^{1}$ \\ ${ }^{1}$ School of Naval Architecture \& Ocean Engineering, State Key Laboratory of Structural Analysis for Industrial Equipment,Dalian \\ University of Technology, Dalian, Liaoning, 116024,China \\ ${ }^{2}$ Collaborative Innovation Center for Advanced Ship and Deep-Sea Exploration, Shanghai,200240,China
}

\begin{abstract}
As wind power technologies become maturer, the monopile foundation of offshore wind turbine is widely used because of its simple structure, few occupied space and low cost. However, under severe sea conditions, the impact of nonlinear wave load applied against the monopile foundation on the system structure safety cannot be ignored. In this paper, the 5MW offshore wind turbine of the National Renewable Energy Laboratory (NREL) was taken as the research object, and the computational fluid analysis software 'STAR$\mathrm{CCM}+$ ' was used to study the hydrodynamic characteristics of the monopile foundation of the wind turbine under different wave parameters. This paper mainly analyzed the upper wave, pressure and wave forces around the monopile foundation of the wind turbine under the same period and different wave heights. And the wave force calculated by CFD was compared with the result based on potential flow theory. The research results showed that with the rise of wave height, the upper wave, pressure and wave force around the monopile foundation increase continuously, and the second-peak phenomenon appeared at some measuring points on the water surface of the monopile foundation. Because the CFD method considers the fluid viscosity and is more in line with the real sea conditions, it is more accurate to obtain wave forces based on this method.
\end{abstract}

\section{Introduction}

In recent years, as global warming and environmental pollution become increasingly serious, the development and utilization of renewable energy has become a trending topic of energy development all over the world. China is rich in offshore wind energy resources, and has huge reserves of exploitable wind energy, thus having the advantages of developing offshore wind power ${ }^{[1]}$. Offshore wind power is an important field of renewable energy development, an important force to promote wind power technical progress and industrial upgrading, and a critical measure to promote the adjustment of energy structure. Accelerating the construction of offshore wind power projects is of great significance for promoting coastal areas to curb environmental pollution, adjust energy structure and transform economic development mode ${ }^{[2]}$.

Among numerous offshore wind power platform foundations, monopile foundation is widely used because of its simple structure, few occupied space and low cost. However, under severe sea conditions, the elastic deformation of the monopile foundation caused by nonlinear wave load cannot be ignored [3]. With the continuous increase of installed capacity, the impact of wave load on monopile foundation becomes increasingly evident. The deformation of monopile foundation will affect the action of surrounding fluid, thus intensifying the vibration of wind turbine blades and monopile foundation.
Wave load has a great effect on the normal operation and service life of wind turbines. Although there are some researches on the hydrodynamic characteristics of monopile foundation, most of them are based on potential flow theory, and the results of numerical simulation may have some errors. Therefore, CFD method is needed for further research ${ }^{[4]}$.

This paper took the $5 \mathrm{MW}$ offshore wind turbine of National Renewable Energy Laboratory (NREL) as the research object, and used the computational fluid analysis software 'STAR-CCM +' to study the upper wave, pressure and wave force around the monopile foundation of the wind turbine under different wave parameters, providing some reference and suggestions for the structural design and stable operation of offshore wind turbines.

\section{Numerical Model}

\subsection{Geometric model}

Table 1 shows the relevant parameters of the 5MW offshore wind turbine model of the National Renewable Energy Laboratory (NREL). The model is scaled according to the ratio of 1:10 during modeling. The model diagram is shown in Figure 1.

\footnotetext{
* Corresponding author:zoulidut@126.com
} 
Table1. Relevant Parameters of NREL 5MW Offshore Wind Turbine Model

\begin{tabular}{|c|c|c|c|}
\hline $\begin{array}{c}\text { Design } \\
\text { Parameters }\end{array}$ & Value & $\begin{array}{c}\text { Design } \\
\text { Parameters }\end{array}$ & Value \\
\hline Rated Power & $5 \mathrm{MW}$ & $\begin{array}{c}\text { Rotor } \\
\text { Diameter and } \\
\text { Hub Diameter }\end{array}$ & $126 \mathrm{~m}, 3 \mathrm{~m}$ \\
\hline $\begin{array}{c}\text { Tower } \\
\text { Height }\end{array}$ & $90 \mathrm{~m}$ & $\begin{array}{c}\text { Cut-in wind } \\
\text { speed, cut-out } \\
\text { wind speed }\end{array}$ & $3 \mathrm{~m} / \mathrm{s}, 25 \mathrm{~m} / \mathrm{s}$ \\
\hline $\begin{array}{c}\text { Nominal tip } \\
\text { speed }\end{array}$ & $80 \mathrm{~m} / \mathrm{s}$ & $\begin{array}{c}\text { Tower bottom } \\
\text { diameter and } \\
\text { tower top } \\
\text { diameter }\end{array}$ & $6 \mathrm{~m}, 3.9 \mathrm{~m}$ \\
\hline Blade Mass & $110 \mathrm{t}$ & Tower Mass & $347 \mathrm{t}$ \\
\hline $\begin{array}{c}\text { Spanwise } \\
\text { length of } \\
\text { blade }\end{array}$ & $62.9 \mathrm{~m}$ & $\begin{array}{c}\text { Dangling } \\
\text { Length }\end{array}$ & $5 \mathrm{~m}$ \\
\hline $\begin{array}{c}\text { Control } \\
\text { Scheme }\end{array}$ & $\begin{array}{c}\text { Variable } \\
\text { Variable } \\
\text { Pitch }\end{array}$ & Drive System & $\begin{array}{c}\text { High-speed } \\
\text { Multistage } \\
\text { Gearbox }\end{array}$ \\
\hline
\end{tabular}

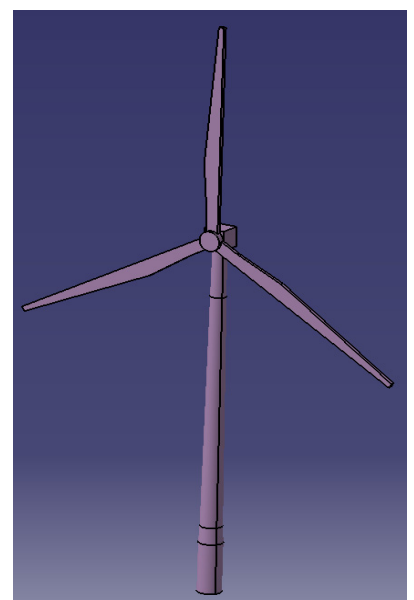

Figure 1. NREL 5MW Wind Turbine Model

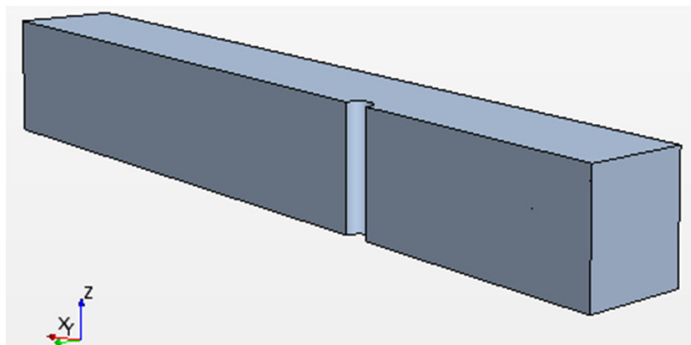

Figure 2. Fluid Domain Geometry

The study targets the hydrodynamic characteristics of monopile foundation and thus does not involve the blade part above water. The monopile foundation and fluid domain geometry are established according to the above parameters and scale ratio. Since the flow field during computation is symmetrical structure, in order to reduce the computational complexity, only half of the domain needs to be analyzed. The computational fluid domain is shown in Figure 2. The whole computational domain is 19.2 meters long, 4 meters wide and 2.5 meters high, in which the axis of pile foundation coincides with the $Z$ axis, and the wave propagates along the positive direction of $X$ axis. Because it involves the free liquid surface of gasliquid flow, $0.5 \mathrm{~m}$ above the still water surface $(Z=0)$ is initially set as the air zone, and $2 \mathrm{~m}$ below the still water surface as the liquid zone.

\subsection{Physical model and mesh generation}

According to the fluid domain geometry in Figure 2, the right end $X=-6.4 \mathrm{~m}$ and the lower end $Z=-2 \mathrm{~m}$ are set as velocity inlet, the left end $X=12.8 \mathrm{~m}$ and the upper end $\mathrm{Z}=0.5 \mathrm{~m}$ are set as pressure outlet, and the front end $\mathrm{Y}=1.25 \mathrm{~m}$ and the rear end $\mathrm{Y}=-1.25 \mathrm{~m}$ are set as symmetry plane. In order to prevent wave reflection, the wave absorbing area is set at the range of $X=6.4 \mathrm{~m} \sim \mathrm{X}=12.8 \mathrm{~m}$. In all examples, the computation time step is set to 0.005 $\mathrm{s}$, the temporal discretization scheme is second-order, and the total simulation time is $12 \mathrm{~s}$.

$\mathrm{K}$-epsilon turbulence model is used for computation. VOF method is used for the treatment of free surface. Finite volume method and SIMPLE method for solving discrete equations are used for governing equations. The wave-making and wave-absorbing methods used are velocity inlet method and damping wave-absorbing method.

Considering the influence of free surface, the grid near the wave surface is densified, and then other areas are divided by increasingly sparse grid. The computation model adopts hexahedral grid, and the number of prismatic layers is 8. In STAR-CCM +, it is recommended that 10-20 grid cells should be divided in the wave height direction ( $Z$ axis) within the wave height range of the Stokes 5 wave. In order to reduce the computational complexity, 16 grids are taken along the wave height direction, and the ratio of grid size in other directions to grid size in the wave height direction within the wave height range is 4 . Because the focus of the research is on changes of upper wave and pressure around the pile foundation, the grid around the pile foundation is appropriately densified. According to the above ideas, the computational domain is divided into grids. The divided computational domain grid is shown in Figure 3.

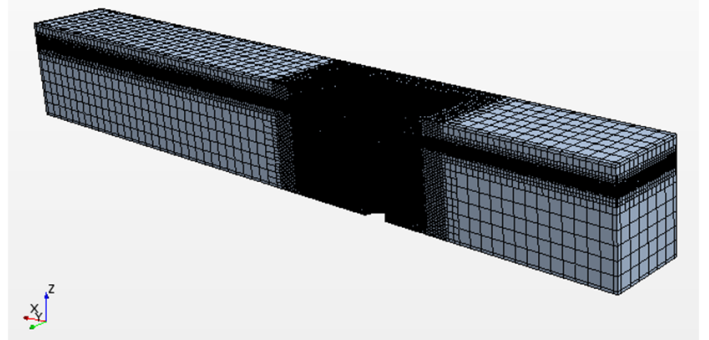

(a) Grid division of the computational domain

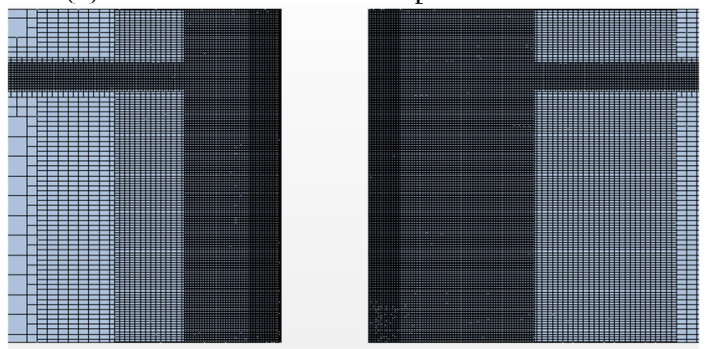

(b) Grid division around monopile foundation

Figure 3. Grid Division 


\subsection{Layout of monitoring points}

In order to better monitor the wave run-up phenomenon on the water surface of monopile foundation, monitoring points are set at intervals of 45 degrees on the water surface. In order to monitor the pressure of some monitoring points of monopile foundation, the monitoring points are established at intervals of 45 degrees in the middle and bottom of monopile foundation. The distribution of monitoring points for monopile foundation is shown in Figure4.
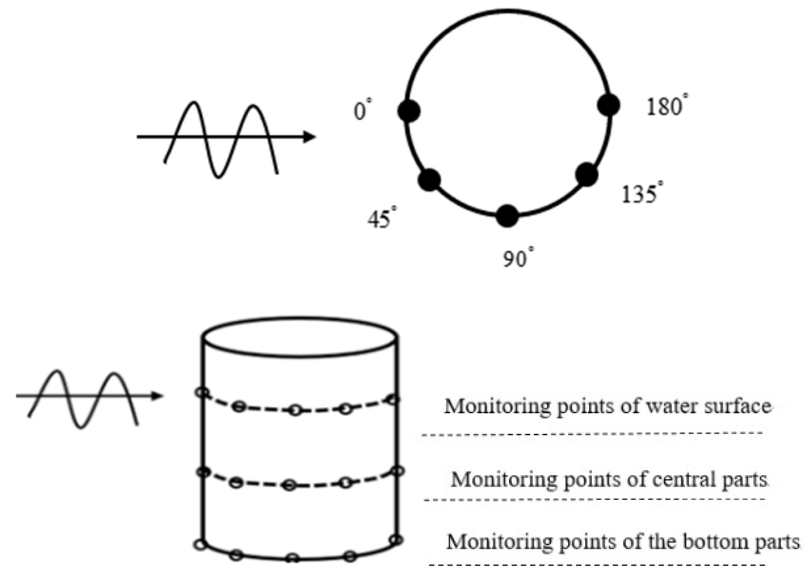

Figure 4. Layout of monitoring points

\subsection{Design condition}

Based on the real marine environment of South China Sea wind power station, typical sea conditions are selected and scaled according to the scale ratio of $1: 10$ to obtain simulated working conditions. The specific wave parameters are shown in Table 2.

Table2. Design Condition

\begin{tabular}{|c|c|c|}
\hline Condition number & Wave height $/ \mathrm{m}$ & Period/s \\
\hline $\mathrm{H} 1$ & 0.15 & 1.4 \\
\hline $\mathrm{H} 2$ & 0.20 & 1.4 \\
\hline $\mathrm{H} 3$ & 0.25 & 1.4 \\
\hline $\mathrm{H} 4$ & 0.30 & 1.4 \\
\hline
\end{tabular}

\section{Results and Analysis of Numerical Simulation}

\subsection{Analysis of Wave Run-up Curve on Water Surface of Monopile Foundation}

Figure 5 shows the duration curve of wave run-up at monitoring points on the water surface of monopile foundation under working condition $\mathrm{H} 4$. It can be seen from Figure 5 that the wave run-up value is the largest at $0^{\circ}$ direction, decreases as the wave moves forward, and reaches a minimum at $135^{\circ}$ direction. Due to the blocking effect of monopile foundation, there is an obvious ridge of water along $180^{\circ}$ direction, and the wave run-up rises to a larger value. At the same time, in the process of wave advancement, due to the blocking effect of gravity and monopile foundation, the waves gathered on the backwave surface of monopile foundation fall back, forming reverberating side waves opposite to the propagation direction of incident waves. The reverberating side waves will meet and overlap with incident waves around monopile foundation, producing second peak phenomenon along $90^{\circ}$ and $135^{\circ}$ direction.

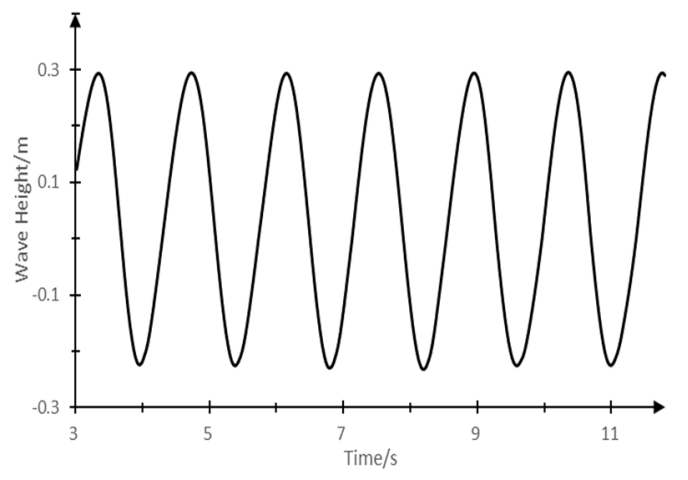

(a) 0 degree on the water surface

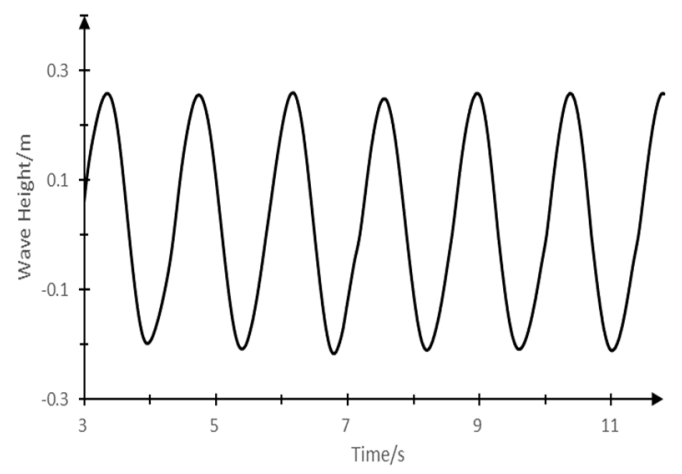

(b) 45 degrees on the water surface

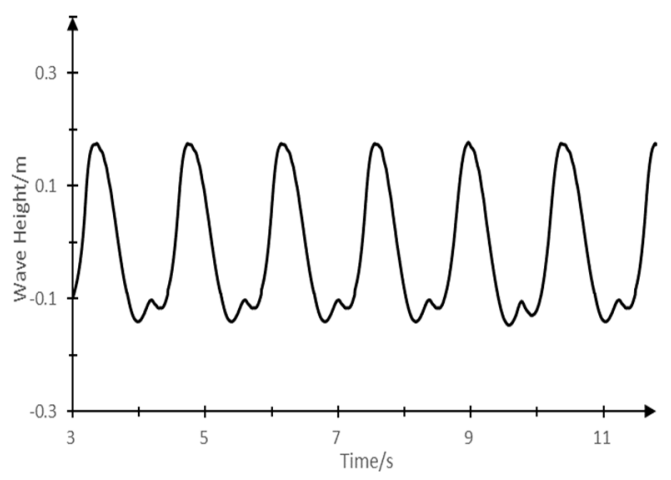

(c) 90 degrees on the water surface

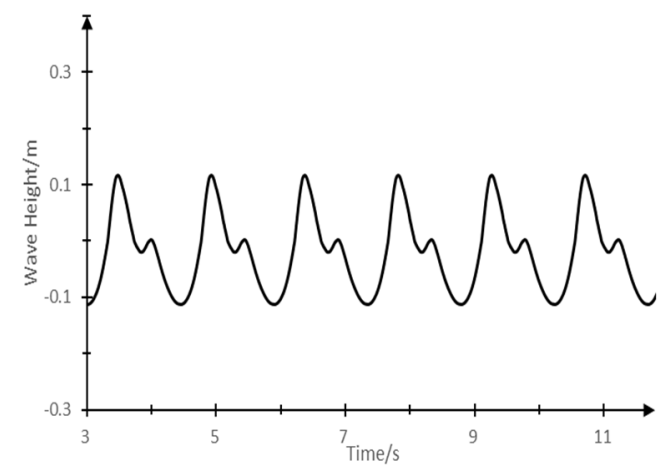

(d) 135 degrees on the water surface 


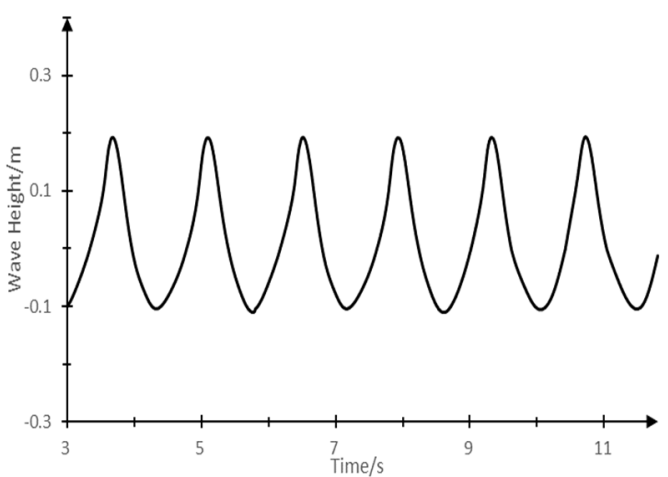

(e) 180 degrees on the water surface

Figure 5. Curve of wave run-up on water surface of monopile foundation

Figure 6 shows the duration curve of wave run-up at monitoring points on the water surface of monopile foundation under different wave heights, and Table 3 shows the wave run-up value at monitoring points on the water surface of monopile foundation under different wave heights. As can be seen from Figure 6 and Table 3, wave run-up value increases with the rise of wave heights, and reaches the maximum value at direction. With the wave moving forward, due to the blocking effect of the monopile foundation in the front, the wave energy begins to dissipate dramatically, and the run-up height decreases rapidly. When it propagates to $90^{\circ}$ direction, the wave has passed through the monopile foundation, and the wave dissipation slows down, so that the wave run-up becomes slower, and the run-up value continues to decrease, reaching the minimum value at $135^{\circ}$. Because the waves on both sides of the monopile form water cresting on the back, so at $180^{\circ}$ the run-up height rises by a larger value, and the overall variation trend is the same as that under the above working conditionH4.

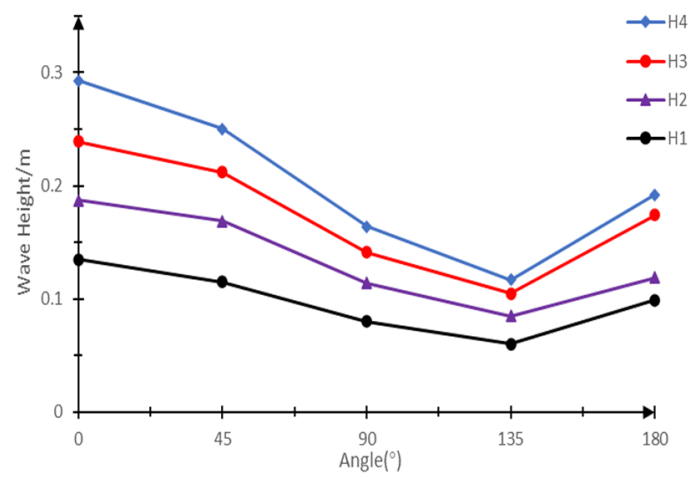

Figure 6. Duration curve of wave run-up at monitoring points on the water surface of monopile foundation under different wave heights

Table3. Wave run-up value at monitoring points on the water surface of monopile foundation under different wave heights

\begin{tabular}{|c|l|l|l|l|l|}
\hline $\begin{array}{c}\text { Dorking } \\
\text { condition }\end{array}$ & $0^{\circ}$ & $45^{\circ}$ & $90^{\circ}$ & $135^{\circ}$ & $180^{\circ}$ \\
\hline H1 & 0.135 & 0.115 & 0.081 & 0.063 & 0.099 \\
\hline H2 & 0.187 & 0.169 & 0.114 & 0.085 & 0.119 \\
\hline H3 & 0.239 & 0.212 & 0.141 & 0.105 & 0.176 \\
\hline H4 & 0.293 & 0.250 & 0.16 & 0.117 & 0.192 \\
\hline
\end{tabular}

\subsection{Pressure Duration Curve Analysis at Monitoring Points of Monopile Foundation}

Figure 7 is a duration curve of pressure at monitoring points of monopile foundation. It can be seen from the figure that the pressure change of the monitoring points around the monopile foundation is in line with the wave run-up tendency mentioned above. The pressure of each monitoring point increases with the rise of wave height. With the increase of water depth, the pressure gradually grows, but the impact of waves on the monopile foundation declines, resulting in the diminishing difference between the monitoring points.

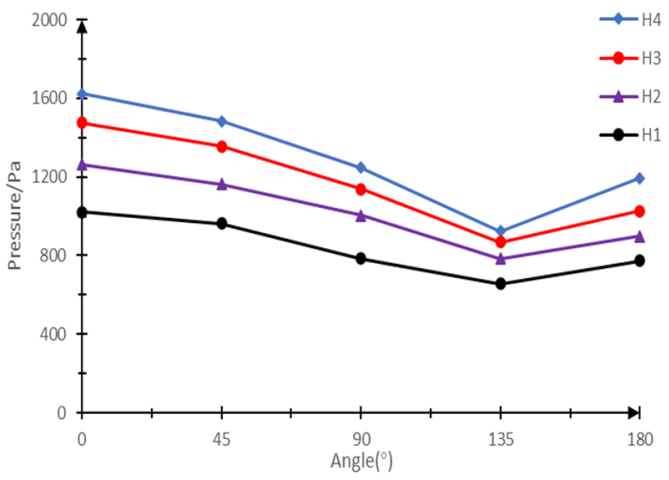

(a) Water surface pressure

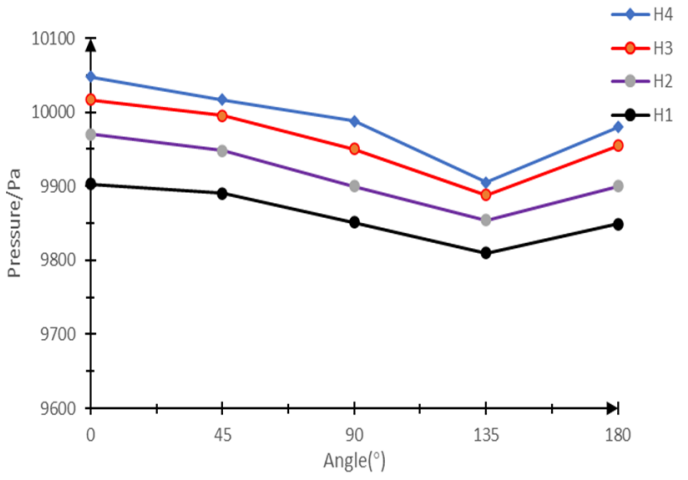

(b) Middle pressure

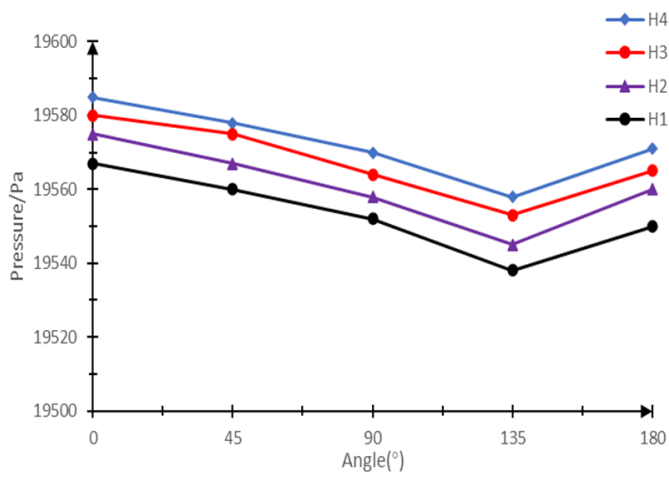

(c) Base pressure

Figure 7. Pressure time history curve of single pile foundation

\subsection{Analysis of Duration Curve of Wave Forces on Monopile Foundation}

Figure 8 is the duration curve of wave forces applied on monopile foundation. It can be seen from the figure that the wave force at the same wave height changes linearly 
and regularly, and the wave force on monopile foundation increases linearly with the rise of wave height.

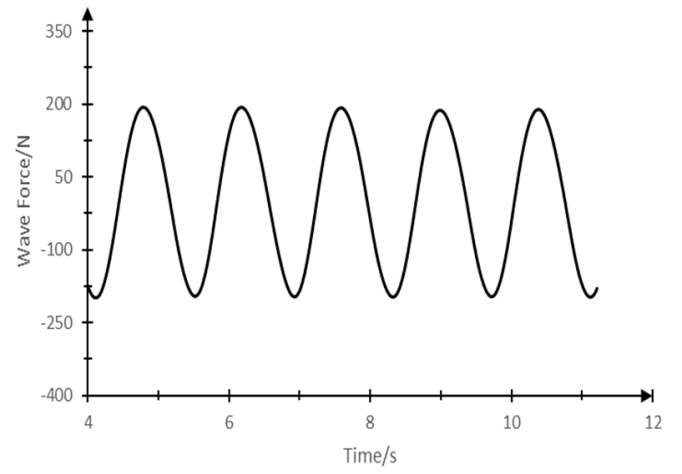

(a) Condition $\mathrm{H} 1$

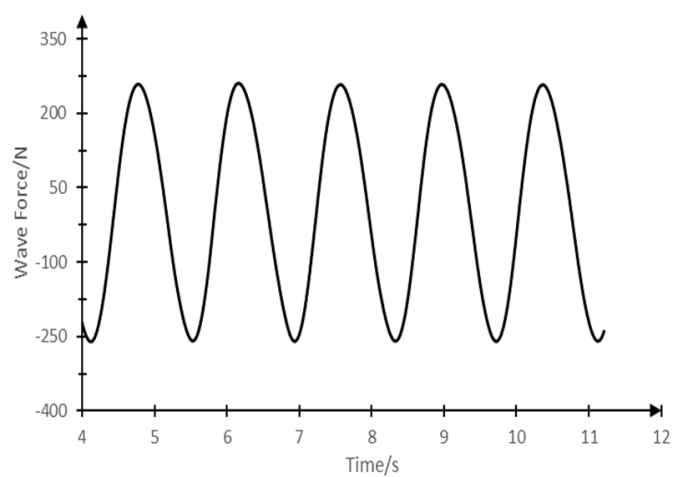

(b) Condition $\mathrm{H} 2$

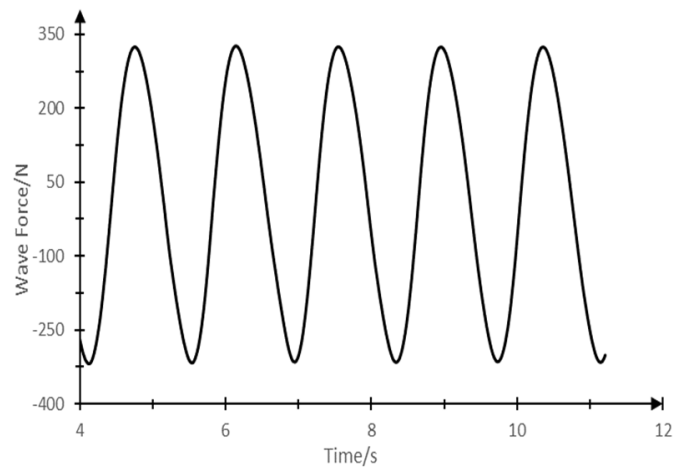

(c) Condition $\mathrm{H} 3$

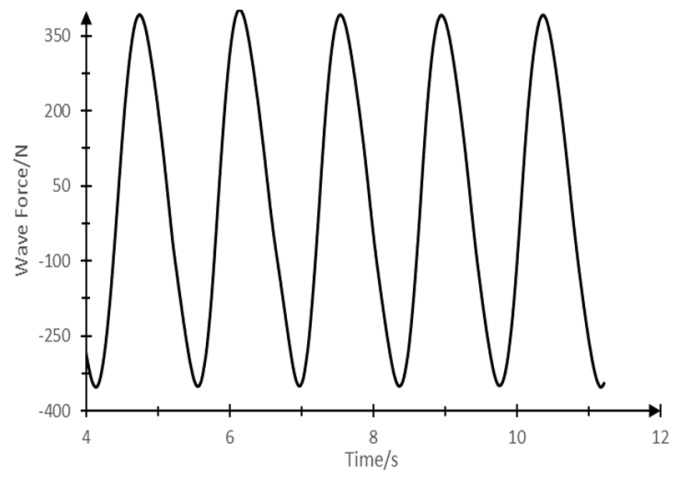

(d) Condition $\mathrm{H} 4$

Figure 8. Time history curve of wave force on single pile foundation

Figure 9 is a comparative analysis of the maximum wave force calculated based on potential flow theory and CFD method. The wave force based on potential flow theory is calculated by AWQA software. It can be seen from the figure that the wave forces calculated by the potential flow theory are larger than those calculated by the CFD method, because the potential flow theory does not consider the viscosity of the fluid and assumes that the fluid does irrotational motion, so that the wave forces obtained are larger. If there is little requirement for computation speed, it is more accurate to solve wave force by CFD method, because calculation by potential flow theory will cause linearization error and make the result deviate from the actual value.

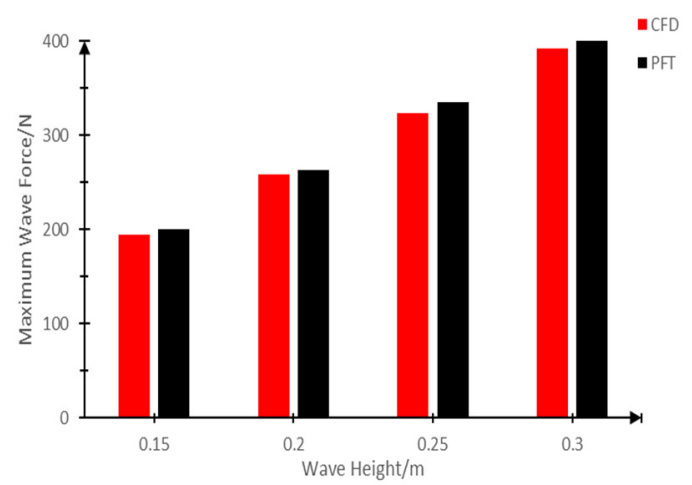

Figure 9. Comparative analysis of wave forces

\section{Conclusions}

This paper has studied the hydrodynamic characteristics of the wind turbine monopile foundation under the action of nonlinear waves through the CFD method, mainly discussed the changes of the upper wave, pressure and wave forces around the monopile foundation, and compared the calculated wave forces with the results based on the potential flow theory. The conclusions are summarized as follows:

1. With the rise of wave height, the wave run-up value around the monopile foundation gradually increases. The run-up value reached a maximum in the monopile foundation along $0^{\circ}$ direction, and then it decreased gradually, reaching a minimum along $135^{\circ}$ direction. Because of the blocking effect of monopile foundation, water cresting is formed on the backwave surface, and the run-up again rose to a larger value along $180^{\circ}$ direction. As the reverberating side wave appears, it meets and overlaps with incident wave on the backwave surface of monopile foundation, and thus there is the second-peak phenomenon.

2. The pressure of monitoring points around the monopile foundation increases with the rise of wave height. With the increase of water depth, the pressure on the monopile foundation gradually grows, but the impact of waves on the monopile foundation gradually decreases, resulting in the diminishing difference between the monitoring points.

3. The wave power exerted on monopile foundation increases linearly with the rise of wave height. The wave forces calculated based on the potential flow theory are all larger than those calculated by the CFD method. If there is little requirement for the computation speed, it is more accurate to solve the wave forces by the CFD method, and calculation by the potential flow theory will cause linearization errors and make the results deviate from the actual values. 


\section{Acknowledgments}

This research is supported by the Australia-China Joint Research Centre of Offshore Wind and Wave Energy Harnessing Project (2017YFE0132000).

\section{References}

1. Li Haozhang, Liu Pingyuan, Wang Jinhong, et al. Analysis of the development status and future prospects of China's wind power industry. Mechanical and Electrical Information. 2020.

2. Bredmose H, Sahlberg-Nielsen L, Slabiak P, et al. Dynamic excitation of monopiles by steep and breaking Waves. Experimental and numerical study. Proceedings of the ASME 32nd international conference on ocean, offshore and arctic engineering, Nantes, frances. 2013.

3. Tang Ye. Study on hydrodynamic characteristics of large offshore monopile fan under high-amplitude nonlinear wave. Liaoning: Dalian University of Technology. 2019.

4. Gu Jiayang, Xie Yulin. Numerical simulation of wave slamming load on deep-water semi-submersible platform under regular waves. China's Society of Naval Architecture and Marine Engineering. The 29th National Conference on Hydrodynamics.

5. Sun Bowen, Li Ye. Research on fixed large-diameter monopile foundation of an inshore wind turbine under sea loads. Ship Science and Technology. 2018. 